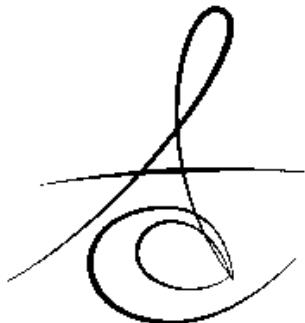

Makale Kodu/Article code: 1902

Makale Gönderilme tarihi: 17.10.2014

Kabul Tarihi: 24.02.2015

\section{İNDİREK POSTERİOR RESTORASYONLAR}

\section{INDIRECT POSTERIOR RESTORATIONS}

Dt. Derya Merve HALAÇOĞLU*

Yrd. Doç. Dr. Duygu TUNCER*

Prof. Dr. Neslihan ARHUN*

\section{ÖZET}

Hasta ve hekimlerin estetik ve uzun ömürlü restorasyonlarla ilgili beklentisindeki artış, adeziv rezin simanlar ile diş dokusu ve diğer restoratif materyallere bağlanabilen, indirek estetik posterior restorasyonların kullanımını arttırmıştır. Bu derlemede, indirek restoratif tekniklerin tanıtılması ile birlikte, indirek porselen ve rezin kompozit restorasyonların, endikasyon ve kontrendikasyonları, avantaj ve dezavantajları farklı açılardan karşılaştırılmaktadır; porselen ve kompozit rezinler, estetik görüntüleri, uzun klinik ömürleri, dayanıklı olmaları, daha az mikrosızıntı ve postoperatif hassasiyet göstermeleri nedeniyle indirek restorasyonlarda kullanılmaya uygun materyallerdir.

Anahtar kelimeler: Porselen, kompozit rezin, indirek restorasyon

\section{GİRİs}

Estetik indirek posterior restorasyonlar, restoratif diş tedavileri arasında geniş ve önemli bir yer tutmaktadır. Bu restorasyonların gelişmiş ve doğal görüntüsü, artan hasta beklentilerini karşılamaktadır. Direk yöntemle uygulanan kompozit rezin restorasyonlar konservatif posterior restorasyonlardır. Bu tekniğin felsefesi sadece çürük diş dokusu uzaklaştırılmasına ve kompozit rezin ile restore edilmesine dayanmaktadır. Ancak, direk teknikle uygulanan kompozit rezinlerin polimerizasyon sırasında büzülmesi sonucu ortaya çıkan gerilme kuvvetleri dişte post-operatif hassasiyete, mikrosızıntıya ve sekonder çürüğe neden olabilmektedir. ${ }^{1-3}$ Bu sorunları gidermek için porselen veya kompozit rezinler kullanılarak estetik indirek restoras-

\section{ABSTRACT}

The increasing interest of patients' and dentists' esthetic desire and long-lasting restorations led the increased use of indirect esthetic posterior restorations which may bond to tooth structure and other restoratives by means of adhesive resin cements. In this review, along with the definitions indirect restorative techniques, indications and contraindications, advantages and disadvantages of ceramic and resin composite indirect restorations are described. Comparison of ceramic indirect restorations with resin composite indirect restoration have been made from different point of views. Ceramics and composite resins are appropriate restorative materials for indirect restorations because of their esthetic, long clinic lifetime, durability, less microleakage and postoperative sensitivity.

Keywords: Ceramic, composite resin, indirect restorations

yonlar geliştirilmiştir. Restorasyon uygulanacak kavite, direk restoratif teknik uygulamak için uygun değilse, dişi restore etmek için, porselen veya laboratuvar işleminden geçirilmiş indirek kompozit restorasyonlar kullanılabilir. ${ }^{4}$ Porselen ve kompozit indirek restorasyonlar ağız dışında hazırlandıklarından polimerizasyon büzülmesi en aza indirilebilir, ${ }^{5}$ anatomik oluşumları daha belirgin bir çiğneme yüzeyi ve proksimal kontak sağlanabilir. ${ }^{1-3}$

İndirek posterior restorasyon, ağız dışında oluşturulan bir restorasyondur, kavitenin şekline göre inley, onley ve overley olarak adlandırılabilir. İnley; çiğneme yüzeyinin tamamen restorasyon materyali ile örtülmediği ve oklüzal, gingival ve proksimal lezyonların restorasyonunda kullanılan restorasyonlardır. Onley, çiğneme yüzeyinin tamamen restorasyon

\footnotetext{
* Başkent Üniversitesi Diş Hekimliği Fakültesi Restoratif Diş Tedavisi Anabilim Dalı, ANKARA; TÜRKİYE
} 
materyali ile örtüldüğü restorasyondur. Overley ise; çiğneme yüzeyine ek olarak bukkal ve lingual yüzeylerin de restorasyon materyali ile örtüldüğü restorasyondur. ${ }^{6}$

İndirek restorasyonların, ağız içinde yapılmasını sağlayan birkaç farklı teknik olsa da, indirek restorasyonlar çoğunlukla laboratuvarda hazırlanır. ${ }^{7}$ Adeziv diş hekimliğindeki büyük gelişmeler, aşırı madde kayıplı dişlerde yapılan geleneksel restorasyonların yerini dentin ve mine dokusuna adezyon yoluyla bağlanan indirek restorasyonların almasını sağlamıştır. Dentin ve mineye adeziv tekniklerle bağlanan indirek restorasyonlar az miktarda diş dokusu kaldırılması ile yeterli retansiyon elde edilmesini sağlar. ${ }^{8,9}$

Estetik inley ve onleyler için kavite preparasyonunda bizotaj ve retansiyon formları gerekmemektedir. Kavite duvarları birbirine paralel ve aksiyal duvarlar da tutuculuğu bozmayacak şekilde yukarıya doğru genişler formda olmalıdır. Preparasyondaki düzensizlikler sağıklı diş dokusu uzaklaştırılarak elimine edilmemeli, rezin veya rezin modifiye cam iyonomer siman ile block-out yapılmalıdır. Aksiyal duvarlar arasındaki genişlik en az 2 mm olmalıdır. ${ }^{10}$

\section{Indirek Kompozit Rezin Restorasyonlar}

Kompozit rezin materyallerde polimerizasyon oranını arttırmak amacıyla indirek restorasyon yapıması günümüzde oldukça önem kazanmıştır. Dietschi ve arkadaşlarının ${ }^{11}$ yaptıkları bir çalışmada restorasyonun ağız dışında bitirildikten sonra kaviteye uygulanmasıyla direk kompozit rezin uygulamalarında ortaya çıkan birçok problemin üstesinden gelinebileceği bildirilmiştir. Ayrıca başka bir çalışmada, posterior dişlerin restorasyonunda indirek inley tekniklerinin kullanımı direk tekniğe oranla daha zor ve zaman alıcı olmasına rağmen kenar sızdırmazlığının sağlanmasında etkin yöntemlerden biri olarak kabul edilebildiği sonucuna ulaşılmıştır. ${ }^{5}$

Kompozit rezin materyallerde, indirek sistemlerinin uygulanmasındaki esas amaç, materyalin polimerizasyon sırasındaki büzülmesini önlemek veya azaltmak ve dişle iyi bir bağlantı oluşturmaktır. Yeni adeziv sistemlerinin geliştirilmesi ile indirek restorasyonlar başarılı bir şekilde uygulanmaktadır. Ayrıca kompozit rezinde oluşan kenar açıklığına neden olan polimerizasyon büzülmesinin en aza indirilmesi ile birlikte polimerde arta kalan reaksiyona girmemiş artık monomerlerin miktarının azalması da tekniğin mekanik özelliklerini iyileştirir. ${ }^{11-14}$
Ozakar-Ilday ve arkadaşları $^{15} 2013$ yılında yayınladıkları bir klinik araştırmada indirek kompozit restorasyonların klinik performansını değerlendirmişlerdir. Çalışmada toplamı 60 olan hem direk hem indirek kompozit restorasyonu 3 yıl takip etmişlerdir. Çalışmanın sonucunda indirek restorasyonların, direk restorasyonlara göre daha iyi klinik skorlar gösterdiğini bildirmişlerdir.

\section{Endikasyon ve Kontrendikasyonları:}

Genel olarak indirek restorasyonlar OM, OD veya MOD inley/onley olarak premolar veya molar dişlerde uygulanabilir. Ağız hijyeni iyi olan, amalgama karşı alerjisi olan hastalarda, ağzında farklı materyallerden yapılmış restorasyonları olan (galvanik akımın meydana gelebileceğini düşündüğümüzde), estetik kriterlerin ön planda olduğu vakalarda, geniş madde kaybı olan dişlerde ancak bağlanma için uygun ve yeterli diş dokusu olması ve rezin bazlı restorasyonun dişin geri kalanını koruyup güçlendirmesi şartı ile yapılabilir.

Ancak indirek kompozit restorasyonların bazı durumlarda kullanılması uygun değildir. Bu durumlar; ağız hijyeninin yeterli olmadığı hastalar, kalan diş dokusunun yeterli olmadığı ya da, tüberkül kırıkları, bruksizm ve benzeri alışkanlıkları olan hastalarda kullanımı uygun değildir. Kavitede undercut varlığında da kullanımı tercih edilmez. ${ }^{16}$

\section{Avantaj ve Dezavantajları:}

İndirek kompozit restorasyonların, alternatif yöntemlere göre birçok avantajı vardır. Bu tip restorasyonlar estetik restorasyonlardır ve ağız dışında oluşturulmaları sayesinde polimerizasyon büzülmesi direk posterior kompozit restorasyonlardan daha az miktardadır ve yan dişle kurulan kontakt ilişkisi daha başarılı olur. Kompozit indirek restorasyonların laboratuvar işlemleri porselen indirek restorasyonlardaki kadar uzun ve zahmetli değildir. Diş yapısına adeziv sistemlerle bağlandıkları için daha fazla diş dokusu korunur ve dişin direnci artar. ${ }^{16}$

İndirek kompozit restorasyonların avantajlarının yanında, klinik bazı olumsuz özellikleri vardır. Bu restorasyonlar, direk kompozit rezin uygulamalarındaki kadar kısa sürede olmasa dahi su emme özellikleri vardır ve zamanla renk değiştirdikleri bilinmektedir. Aşınmaya karşı ise dirençleri düşüktür. ${ }^{16}$

\section{Indirek Porselen Restorasyonlar}

İndirek porselen restorasyonların gelişimi adeziv diş hekimliğindeki gelişmelerle paralel

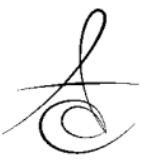


ilerlemiştir ve indirek porselen restorasyonların dişe rezin simantasyon ile bağlanması, bu restorasyonların kırılmaya ve okluzal kuvvetlere karşı direncini arttırmaktadır. ${ }^{1}$ Bu yöntemde kompozit restorasyonların aksine polimerizasyon büzülmesi çok ince bir tabaka rezin siman ile sınırlıdır. Rezin siman kalınlığının çok ince olması kenar uyumunun, dayanıklıığın ve estetiğin artmasını sağlar ve böylece bağlanma, başarılı ve uzun süreli olur. ${ }^{17}$

İndirek porselen restorasyonlar birçok klinik araştırma ile değerlendirilmiştir. Santos ve arkadaşlarl $^{18}$ iki farklı sistemle yapılan -sinterlenmiş Duceram (Dentsply-Degussa) ve preslenebilir IPS Empress (Ivoclar Vivadent, AG, Schaan, Lichtenstein)- porselen inley ve onleylerin 5 yıllık klinik performansını değerlendirmiştir. 35 hastaya 86 restorasyon dual-cure rezin simanla (Variolink II, Ivoclar Vivadent, Ellwagnen, Almanya) ve Syntac Classic adeziv (Ivoclar Vivadent, AG, Schaan, Lichtenstein) kullanılarak uygulanmıştır. 5 yıllık takiplerinde, Duceram ve IPS Empress porselen sistemler arasında anlamlı fark bulunmamıştır ve her iki tip porselen materyal de kabul edilebilir klinik performans sergilemiştir.

Kramer ve arkadaşları ${ }^{19}$ farklı iki adeziv rezin kompozit kombinasyonunun, IPS Empress inleylerin yapıştırmasındaki etkilerini klinik olarak incelemişlerdir. 94 IPS Empress restorasyon 31 hastaya, EBS Multi/ Compolute (3M ESPE, St.Paul, MN, ABD) veya Syntac/Variolink II (Ivoclar Vivadent AG, Schaan, Lichtenstein) ile uygulanmıştır ve 4 yıl takip edilmiştir. Porselen inleylerin yapıştırılmasında iki yapıştırma simanı arasında istatistiksel anlamlı fark bulunmamıştır ve 4 yıl sonunda başarısızlık oranı \% 4 olarak belirlenmiştir.

Frankenberger ve arkadaşları ${ }^{20}$ lösitle güçlendirilmiş cam porselen inley ve onleylerin (IPS Empress, Ivoclar Vivadent AG, Schaan, Lichtenstein) 12 yıllık klinik değerlendirmesini yaptıkları çalışmalarında 96 porselen inley ve onley 34 hastaya bir adeziv (Syntac, Ivoclar Vivadent AG, Schaan, Lichtenstein ) ve dört farklı yapıştırma kompoziti (Tetric, Variolink Low, Variolink Ultra, Dual Cement, Ivoclar Vivadent AG, Schaan, Lichtenstein) kullanılarak uygulamışlardır. Araştırmanın sonucunda IPS Empress inley ve onleyler başarılı bulunmuştur. Dual-cured rezin kompozitlerle yapıştırılan restorasyonlarda ise kitlesel kırıklar görülmüştür.

\section{Endikasyon ve Kontrendikasyonları:}

İndirek porselen restorasyonlar; tüberkül kırığı ve estetik önemli olduğunda, endodontik tedavi görmüş dişlerde, aşınmanın fazla olduğu bölgelerde, metal restorasyon istemeyen veya metal alerjisi olan hastalarda, geniş ve derin çürük kavitesi bulunan dişlerde, zayıflamış duvarların tüberkül kırıklarına karşı güçlendirilmesi amacıyla, karşıt arkta porselen kron veya köprülerin bulunduğu vakalarda benzer sertlik ve aşınma direncine sahip materyal kullanılması gerektiğinde, bağlanma özelliği olmayan amalgam restorasyonların sıklıkla düştüğü kavitelerde kullanılabilirler. ${ }^{10,16,21-23}$

$\mathrm{Bu}$ restorasyonların klinik uygulamada endike olmadığı durumlar ise; bruksizm gibi kötü alışkanlıkları olan hastalarda, kron boyu kısa olan dişlerde, genç hastaların geniş pulpalı dişlerinde, porselen karşısındaki kompozit rezini aşındıracağından porselen restorasyonun karşıtında geniş bir kompozit rezin restorasyon varsa, küçük sınıf I ve II kaviteleri bulunan azı dişlerinde, ekonomik sınırlamalar olduğunda, restore edilecek dişte kavitenin servikal sınırları subgingival yönde çok aşağıda konumlanıyorsa veya kavitenin yapıştırma sırasında tamamen kuru kalması sağlanamıyorsa ortamdaki nem yapışmayı olumsuz etkileyeceğinden, porselen restorasyonlara alternatif yaklaşımlar düşünülmelidir. ${ }^{16,22,24,25}$

\section{Avantaj ve Dezavantajları:}

İndirek porselen restorasyonların, alternatif tedavi yöntemlerine göre birçok avantajı vardır. Bu restorasyonlar mekanik etkilere karşı dirençlidirler, ağız sıvılarından etkilenmezler, boyutsal olarak ve renk açısından stabildirler, ısısal genleşme katsayısı diş dokusuna yakındır, internal ve yüzeysel olarak boyanabilirler, su emme özellikleri yoktur, glaze yapılmış porselen yüzeyi üzerinde plak birikimi minimum düzeydedir, doğal dişlerdekine benzer şekilde renk ve ışık geçirme özelliğine sahiplerdir ve ısı/elektrik akımını zayıf iletirler. ${ }^{26,27}$

Ancak bunun yanında, indirekt porselen resto rasyonların dezavantajlarına bakıldığında; porselenin rijit bir madde olduğu ve üzerine gelen ekstra yükleri tolere edemediği görülmektedir, gerilim ve makaslama kuvvetlerine karşı dirençsizdir. ${ }^{28}$ Ayrıca, kırılmaya karşı dirençsizdir ve debonding görülebilir, ${ }^{29}$ ayrıca rengi sıklıkla değişmediği için komşu dişlerin zamanla renklenmesi karşısında estetik uyumu bozulur, 
pahalıdır, klinik uyum ve hataların düzeltilmesi risklidir, yeniden şekillendirilmesi gerektiğinde metal destekli yapıdan ayrımı zordur. ${ }^{26,30}$

\section{İndirek Kompozit Rezin ve Porselen Restorasyonların Karşılaştırılması}

İndirek kompozit ve porselen restorasyonların özelliklerinin karşılaştırılması, diş hekiminin kullanacağı yöntemi ve materyali seçerken birçok faktörü değerlendirmesini sağlar.

Estetik açısından değerlendirildiğinde; porselenin, kompozit rezinden daha estetik olduğu düşünülebilir. Estetik açıdan sadece mine dokusu porselenden daha iyidir. Fakat yeni geliştirilen kompozit rezinlerde, günümüzde, renk çeşitliliği (mine renkleri, dentin renkleri, insizal vb.) arttırılmıştır ve setlere dahil edilen boyalar ile mükemmel estetik sonuçlar elde edilebilmektedir. ${ }^{31-34}$

Kompozitlerin kırılmaya karşı olan dirençleri porselenden daha yüksektir. ${ }^{35}$ Restorasyonların ağızda denenmesi sırasında porselende kırılma olabilir. Yapıştırıldıktan sonra da porselen çok sağlam bir yapı kazanmaktadır. Adeziv bağlanma ile porselen kritik deformasyona ulaşamaz (\% 0.1 ) ve porselende kırıma olmaz. Porselen duvar kalınlığının en az $1 \mathrm{~mm}$ olduğu çalışmalarda da adeziv bağlanmanın dental porseleni desteklediği gösterilmiştir. ${ }^{16}$

Restore edilen dişlerin kırılma dayanımlarının restorasyon ve diş yapısı arasındaki bağlantıyı güçlendiren çeşitli faktörlerden etkilendiği ortaya konulmuştur. Yapılan çalışmalarda, adeziv sistemler kullanılarak yapıştırılan indirek kompozit inleyin, dişlerin kırılma dayanımlarının arttırılmasında daha etkili olduğu kanıtlanmıştır. ${ }^{31-33}$ Aşınma direnci açısından karşılaştırıldıklarında; kompozit rezinin aşınma direncinin porselenden oldukça az olduğu görülmektedir. Porselen, mine dokusundan daha sert olduğundan karşıt dişte aşınma görülebilmektedir. ${ }^{36}$ Konvansiyonel porselenlere ve kompozit rezinlere göre dökülebilir cam ve apatit porselenlerin sertlik özellikleri mine dokusuna daha yakındır, bu özellik de bu materyallere üstünlük sağlamaktadır. Porselenin mineyi aşındırması, glaze aşamasının iyi yapılmasıyla engellenebilir. ${ }^{31-34}$

Cao ve arkadaşları ${ }^{37} 2013$ yılında yaptıkları çaIışmada 5 tip kompozit rezinin (1 nanohibrit, 2 mikrohibrit ve 2 tepilebilir kompozit rezin) aşınma direncini ve sertliğini karşılaştırmıştır. Oluşturulan örnekler diş fırçalama makinesinde test edilmiştir. Araştırmanın sonucunda tüm örneklerde istatistiksel olarak anlamlı ölçüde aşınma bildirilmiştir (en az nanohibrit kompozitte ve en çok tepilebilir kompozitte, fakat sertlik ve aşınma arasında istatistiksel olarak anlamlı ilişki bulunamamıştır.

Simantasyon tekniği benzer olduğundan dolayı restorasyonların kenar uyumları başlangıçta aynıdır ve çok iyidir. Ancak kompozitlerin ve diş dokusunun ısısal genleşmelerindeki farklılık nedeniyle, kompozit inleylerde kenar I uyumu daha çabuk bozulmaktadır. Oysaki porselenin ve dökülebilir porselenlerin ISısal genleşmesi mineye eşdeğerdir ve kenar uyumunda bozulma daha az görülmektedir. ${ }^{33}$

Zaruba ve arkadaşları ${ }^{38} 2014$ yılında yaptıkları bir çalışmada porselen ve kompozit inleylerin marjinal adaptasyonunu incelemişlerdir. Çalışmada 50 çekilmiş insan dişine kompozit inley, porselen inley ve direkt kompozit rezin uygulanmıştır ve örneklere termal siklus ile yaşlandırma yapılmıştır. Kenar bütünlüğü taramalı elektron mikroskobu ile değerlendirilmiştir. Çalışmanın sonucunda kompozit ve porselen inley restorasyonların marjinal bütünlüğü, direk yöntemle yerleştirilen kompozit restorasyonlardan daha başarılı bulunmuştur.

Porselen ağız ortamı için çok uygun bir materyaldir, biyouyumludur. Kimyasal olarak inert olup, toksik değildir. Sıvı emilimi yoktur. Dokular tarafından çok iyi tolere edilir. Bu özellikleri nedeniyle kompozit rezinlerden daha üstündür. ${ }^{16}$ İndirek porselen restorasyonların hazırlanması kompozitle karşılaştırıldığında zaman alıcı ve güçtür, teknikleri büyük hassasiyet gerektirir. Kompozit rezin restorasyon hazırlamak hem daha kolay, hem de daha az risklidir. Yapıştırma sonrası yapılan oklüzal düzenlemeler indirek restorasyonların polisajının bozulmasına yol açar. Kompozit rezinlerin tekrar polisajlanması porselenden daha kolaydır. Ancak, Tunçdemir ve arkadaşları ${ }^{39}$ yaptıkları in vitro çalışmada kullandıkları polisaj yönteminin hem kompozit hem porselen yüzeyindeki pürüzlülüğü arttırdığını, ancak kompozit ve porselenin yüzey pürüzlülükleri arasında fark olmadığını belirtmişlerdir. Kompozit polisajı, ince pomza ve kalay oksit ile kolayca yapılabilir. Ancak geliştirilen polisaj patları ve lastiklerle porselende de istenilen yüzey parlaklığına ulaşmak mümkün olmaktadır. ${ }^{16}$

Özet olarak, kompozit ve porselen restorasyonlar karşılaştıııldığında, kompozit indirek restorasyonlar karşıt dişte daha az aşınmaya neden olmaktadırlar, ancak materyalin aşınma direnci, okluzal streslere karşı

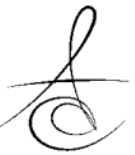


dayanıkılığı porselenden daha azdır. İndirek kompozit rezin restorasyon preparasyonu daha konservatiftir, kavitenin hazırlanması sırasında çürüğün uzaklaştıııması ve minimal preparasyon yeterli olmaktadır, tamir edilebilmektedir. Yapım tekniği indirek porselen restorasyonlarda daha zordur, porselenler pahalı ve daha pahalı ekipmanlarla yapıldığından daha az tercih edilmektedir. Porselen restorasyonların, bitirme ve polisaj işlemleri indirek kompozit rezin restorasyonlarda daha kolaydır. ${ }^{40,41}$

\section{SONUÇ}

Diş rengindeki materyallerdeki ve adeziv sistemlerdeki gelişmeler restoratif diş hekimliğinin uygulama alanını genişletmişlerdir. Artan estetik gereksinimler nedeniyle indirek posterior restorasyonların kullanımı da artmıştır. Biyouyumluluk, dayanıklık, kenar bütünlüğü ve estetikteki gelişmelere rağmen indirek restorasyonların başarısı doğru endikasyona, uygun materyal seçimine, doğru ve hassas tekniğe ve hasta tercihlerine bağlıdır.

\section{KAYNAKLAR}

1. Freedman G. Contemporary esthetic dentistry. $1^{\text {st }}$ ed, Mosby, Inc., an imprint of Elsevier Inc., St.Louis,Missouri 2012, p.469-74.

2. St-Georges AJ, Sturdevant Jr, Swift Jr EJ, Thompson JY. Fracture resistance of prepared teeth restored with bonded inlay restorations. J Prosthet Dent 2003; 89: 551-7.

3. Manhart J, Scheibenbogen-Fuchsbrunner A, Chen HY, Hickel R. A 2-year clinical study of composite and ceramic inlays.Clin Oral Investig. 2000;4: 1928.

4. Roulet JF, Spreafico R. Esthetic posterior indirect restorations In:Roulet JF, Wilson NHF, Fuzzi M. Advances in Operative Dentistry. Contemporary Clinical Practice. Quintessence Publishing Co, Inc, Illionis 2001, p.165-190.

5. Özakar İlday N, Urvasızoğlu N, Seven N. İndirekt kompozit inley restorasyonlar ile direkt kompozit restorasyonların mikrosızıntı yönünden karşılaştırıması. Atatürk Üniv Dis Hek Fak Derg 2009; 19: 76-84

6.Shillinburg HT. Fundementals of Fixed Prosthodontics, 3rd ed, Quintessence Publishing Co. Illinois 1997, p.171-79
7. Qualtrough AJE, Satterthwaite JD, Morrow LA, Brunton PA. Principles of operative dentistry, Blackwell Munksgaard, a Blackwell Publishing company, Corwall 2005; 107-26

8. Van Dijken JW, Hasselrot L, Ormin A, Olofsson AL. Restorations with extensive dentin/enamel bonded ceramic coverage. A 5 year follow-up. Eur J Oral Sci 2001; 109:222-9.

9. Van Dijken JW. All-ceramic restoration: classification and clinical evaluation. Compend Contin Educ 1999; 20:1115-26.

10. Gemalmaz D. Use of heat-pressed, leucitereinforced ceramic on anterior and posterior onlays: A clinical report. J Prosthet Dent 2002; 87: 133-5.

11.Dietschi D, Bindi G, Krejci I, Davidson C. Marjinal and Internal Adaptation of Stratified CompomerComposite Class II Restorations. Oper Dent 2002; 27: 500-9.

12.Türkün S, Demirbas Kaya A. Sıkışıııllabilen Kompozit Rezinlerde Mikrosızıntının In Vitro Olarak Degerlendirilmesi. Hacettepe Üniversitesi Dishekimligi Fakültesi Dergisi 2002; 26: 10-8.

13.Özcan M, Pfeiffer P, Nergiz I. Marjinal Adaptation of Ceramic Inserts After Cementation. Oper Dent 2002; 27: 132-6.

14. Malmström $H$, Schlueter M, Roach T, Moss M.E. Effect of Thickness of Flowable Resins on Marginal Leakage in Class II Composite Restorations. Oper Dent 2002; 27: 373-80.

15. Ozakar-Ilday N, Zorba YO, Yildiz M, Erdem V, Seven N, Demirbuga S. Three-year clinical performance of two indirect composite inlays compared to direct composite restorations. Med Oral Patol Oral Cir Bucal 2013; 18:521-8.

16. Zaimoglu A, Can G. Sabit Protezler, Ankara Üniversitesi Basımevi, Ankara, 2004, p.165-180.

17. Mak YF, Lai SC, Cheung GS, Chan AW, Tay FR, Pashley DH. Micro-tensile bond testing of resin cements to dentin and an indirect resin composite. Dent Mater 2002;18: 609-21.

18. Santos MJ, Mondelli RF, Navarro MF, Francischone $\mathrm{CE}$, Rubo JH, Santos GC Jr. Clinical evaluation of ceramic inlays and onlays fabricated with two systems: five-year follow-up. Oper Dent 2013; 38:3-11.

19. Krämer N, Ebert J, Petschelt A, Frankenberger R. Ceramic inlays bonded with two adhesives after 4 years. Dent Mater 2006; 22:13-21. 
20.Frankenberger $R$, Taschner $M$, Garcia-Godoy $F$, Petschelt A, Krämer N. Leucite-reinforced glass ceramic inlays and onlays after 12 years. J Adhes Dent 2008; 10:393-8.

21. Rosentritt M, Behr M, Handel G. Fixed partial dentures: all ceramics, fibre-reinforced composites and experimental systems. J Oral Rehabil 2003; 30: 873-7.

22.Yüksel G, Çekiç C, Özkan P. Metal desteksiz porselen sistemleri. Atatürk Üniv Dis Hek Fak Derg 2000;10: 79-88.

23.Akın E. Diş Hekimliğinde porselen. İ Ü Diş Hek Fak Yayınları, İstanbul, 1999;35-42.

24.Burgess JO, Haveman CW, Butzin C. Evaluation of resins for provisional restorations.Am J Dent. 1992;5: 137-9.

25.Wall JG, Cipra DL. Alternative crown systems. Dental Clinics of North America 1992;36: 765-82.

26.Soares C.J, Soares P.V, Pereira J.C, Fonseca R.B. Surface Treatment Protocols in the Cementation Process of Ceramic and Laboratory-Processed Composite Restorations: A Literature Review. J Esthet Restor Dent 2005; 17: 224-35.

27.Yamanel K, Caglar A, Gülsahi K, Ozden UA. Effects of different ceramic and composite materials on stress distribution in inlay and onlay cavities: 3-D finite element analysis.Dent Mater J. 2009;28: 661-70.

28.Schaefer O, Watts DC, Sigusch BW, Kuepper H, Guentsch A Marginal and internal fit of pressed lithium disilicate partial crowns in vitro: a threedimensional analysis of accuracy and reproducibility. Dent Mater. 2012;28: 320-6.

29.Gresnigt MM, Kalk W, Ozcan M. Randomized clinical trial of indirect resin composite and ceramic veneers: up to 3-year follow-up. J Adhes Dent 2013; 15: 181-90.

30.Fron Chabouis $\mathrm{H}$, Smail Faugeron V, Attal JP. Clinical efficacy of composite versus ceramic inlays and onlays: a systematic review. Dent Mater. 2013;29: 1209-18.

31.St-Geoerges Annie J, Sturdevant John R, Swift Jr Edward J, Thompson Jeffrey Y. Fracture resistance of prepared teeth restored with bonded inlay restorations. J Prosthet Dent 2003; 89: 551-7.

32. Dalpino PHP, Francischone $C E$, Ishikiriama $A$, Franco EB. Fracture resistance of teeth directly and indirectly restored with composite resin and indirectly restored with ceramic materials. Am J Dent 2002; 15: 389-94.

33.Behr M, Rosentritt M, Ledwinsky E, Handel G. Fracture resistance and Marginal Adaptation of Conventionally Cemented Fiber-Reinforced Composite Three-Unit FPDs. The Int J Prosthodont 2002; 15: 467-72.

34. Hürmüzlü $F$, Hergüner Siso $S$, Isın D. Sınıf II Restorasyonlarda Beş Restoratif Materyalin Mikrosızıntı Degerlendirmesi. Cumhuriyet Üniversitesi Dishekimligi Fakültesi Dergisi 2002; 5: 67-70.

35.Scherer W, Putter $H$, Cooper $H$. Clinical technique for an in-office porcelain modification. J Esthet Dent. 1991;3:23-6.

36.Palmer DS, Barco MT, Pelleu GB Jr, McKinney JE. Wear of human enamel against a commercial castable ceramic restorative material. J Prosthet Dent. 1991;65:192-5.

37.Cao L, Zhao X, Gong X, Zhao S. An in vitro investigation of wear resistance and hardness of composite resins. Int J Clin Exp Med 2013; 6:42330.

38.Zaruba M, Kasper R, Kazama R, Wegehaupt FJ, Ender A, Attin T, Mehl A, Marginal adaptation of ceramic and composite inlays in minimally invasive mod cavities. Clin Oral Investig 2014;18:579-87.

39.Tunçdemir AR, Yavuz M, Polat S, Tunçdemir MT, Özcan E. Effect of air-flow polishing on surface roughness of composites and porcelains. Atatürk Üniv Dis Hek Fak Derg 2012; 22: 242-6

40.El-Mowafy O. Management of extensive carious lesions in permanent molars of a child with nonmetallic bonded restorations-a case report. ] Can Dent Assoc 2000; 66, 302-7.

41.Schmidseder J, Söderholm KJ, Composite Inlays. Color Atlas of Dental Medicine, Aesthetic Dentistry. Ed. Georg Thieme Verlag Stuttgart 2000; 149-62.
Yazışma Adresi
Yrd.Doç.Dr.Duygu Tuncer
Başkent Üniversitesi Diş Hekimliği Fakültesi
Restoratif Diş Tedavisi Anabilim Dalı
11.sokak No:26
06490 - Bahçelievler / ANKARA
Telefon: (312) 2151336
Faks: (312) 2152962
E-posta: dtduygutuncer@gmail.com 